\title{
Mycobacterium abscessus enfeksiyonu yönetimi: Makrolid ve kinolon desensitizasyonu
}

\author{
Kurtuluş $\operatorname{AKSU}^{1}$ (ID) \\ Dilek ÇUHADAR \\ ERÇELEBi ${ }^{1}$ \\ Şeref ÖZKARA ${ }^{2}(I D)$ \\ Süleyman \\ TÜRKYILMAZ ${ }^{1}$ (ID) \\ ilkay KOCA KALKAN ${ }^{1}(I D)$ \\ Özlem \\ ÖZDEDEOĞLU ${ }^{1}($ ID) \\ Buket BAŞA \\ AKDOĞAN $^{\mathbf{1}}($ ID) \\ Hale $\operatorname{ATES}^{\mathbf{1}}$ (ID) \\ Gözde KÖYCÜ \\ BUHARi $^{1}($ ID)
}

${ }^{1}$ Sağlık Bilimleri Üniversitesi, Ankara Atatürk Göğüs Hastalıkları ve Gögüs Cerrahisi Eğitim ve Araştırma Hastanesi, Göğüs Hastalıkları, İmmünoloji ve Alerji Hastalıkları Kliniği, Ankara, Türkiye

${ }^{1}$ Clinic of Chest Diseases, Immunology and Allergic Diseases, Ankara Atatürk Chest Diseases and Chest Surgery Training and Research Hospital, University of Health Sciences, Ankara, Turkey

${ }^{2}$ Sağlık Bilimleri Üniversitesi, Ankara Atatürk Göğüs Hastalıkları ve Göğüs Cerrahisi Eğitim ve Araştırma Hastanesi, Tüberküloz Kliniği, Ankara, Türkiye

${ }^{2}$ Clinic of Tuberculosis, Ankara Atatürk Chest Diseases and Chest Surgery Training and Research Hospital, University of Health Sciences, Ankara, Turkey
Makale atıfi: Aksu K, Çuhadar Erçelebi D, Özkara Ş, Türkyılmaz S, Koca Kalkan i, Özdedeoğlu Ö ve ark. Mycobacterium abscessus enfeksiyonu yönetimi: Makrolid ve kinolon desensitizasyonu. Tuberk Toraks 2021;69(3):399-402

Yazışma Adresi (Address for Correspondence)

\section{Dr. Kurtuluş AKSU}

Sağlık Bilimleri Üniversitesi, Ankara Atatürk Göğüs Hastalıkları ve Gögüs Cerrahisi Eğitim ve Araştırma Hastanesi, Göğüs Hastalıkları, Immünoloji ve Alerji Hastalıkları Kliniği,

ANKARA - TÜRKIYE

e-mail: kurtulusaksu@yahoo.com

OTelif Hakkı 2021 Tüberküloz ve Toraks. Makale metnine www.tuberktoraks.org web adresinden ulaşılabilir.
ÖZ

Mycobacterium abscessus enfeksiyonu yönetimi: Makrolid ve kinolon desensitizasyonu

Antibiyotik aşırı duyarlılık reaksiyonları belirgin morbidite, mortalite ve yetersiz tedavi seçeneklerine yol açabilir. Mycobacterium abscessus enfeksiyonu en sık olarak akciğerleri tutan, tedavi edilmediği takdirde progresyon gösteren ve organizmanın pek çok antibiyotiğe dirençli olmasının yanı sıra tedavide kullanılan ajanların da istenmeyen yan etkilere yol açabilmesi nedeniyle klinisyenler için yönetimi güç bir enfeksiyondur. Makrolidler alerjik reaksiyonlar açısından en güvenilir antibiyotik gruplarından biri olmasına rağmen, Mycobacterium abscessus akciğer hastalığı tedavisinde kullanılan temel antibiyotiklerden birisi olan makrolidlere karşı gelişebilecek erken tip hipersensitivite reaksiyonları, hastalığın tedavi yönetimini güçleştirebilir. Kinolon kullanımının son yıllarda hızla artmasına bağlı olarak bu ajanlar ile alerjik reaksiyon gelişme sıklığı da artmaktadır. Antibiyotik aşırı duyarlılı̆ı saptanan olgularda sorumlu ajanın kullanılmasından kaçınılması gerekmekle birlikte farklı tedavi seçeneği bulunmayan olgularda desensitizasyon gerekli olabilmektedir. Mycobacterium abscessus akciğer hastalığı tanısı konulan ve tedavi başlandıktan sonra klaritromisin ve moksifloksasin ile anafilaksi gelişen bir hastada bu ilaçlarla yapılan başarılı desensitizasyon olgusunu sunuyoruz.

Anahtar kelimeler: Aşırı duyarlılık reaksiyonu; desensitizasyon; kinolon; makrolid; Mycobacterium abscessus 


\begin{abstract}
Mycobacterium abscessus infection management: Macrolide and quinolone desensitization

Antibiotic hypersensitivity reactions can lead to marked morbidity, mortality and inadequate treatment options. Mycobacterium abscessus infection is a difficult management system for clinicians since it most commonly involves the lungs, progresses if untreated, and the organism is resistant to many antibiotics, as well as the agents used in treatment can cause undesirable side effects. Although macrolides are one of the most reliable antibiotic groups in terms of allergic reactions, early type hypersensitivity reactions against macrolides, one of the main antibiotics used in the treatment of Mycobacterium abscessus lung disease, may make the treatment management of the disease difficult. Due to the rapid increase in the use of quinolone in recent years, the frequency of developing allergic reactions with these agents also increases. In cases where antibiotic hypersensitivity is detected, the use of the responsible agent should be avoided, but desensitization may be necessary in cases without different treatment options. In this study, it was aimed to present a case of successful desensitization with clarithromycin and moxifloxacin in a patient who was diagnosed with Mycobacterium abscessus lung disease and developed anaphylaxis with clarithromycin and moxifloxacin after treatment was initiated.
\end{abstract}

Key words: Desensitization; hypersensitivity reaction; macrolide; Mycobacterium abscessus; quinolone

\section{Gíriş}

Mycobacterium abscessus enfeksiyonu en sık olarak akciğerleri tutan, tedavi edilmediği takdirde progresyon gösteren ve organizmanın pek çok antibiyotiğe dirençli olmasının yanı sıra tedavide kullanılan ajanların da istenmeyen yan etkilere yol açabilmesi nedeniyle klinisyenler için yönetimi güç bir enfeksiyondur (1). Klinik ve Laboratuvar Standartları Enstitüsü (Clinical and Laboratory Standards Institute); makrolidler, aminoglikozidler, florokinolonlar, imipenem, doksisiklin, tigesiklin, cefoksitin, kotrimoksazol ve linezolid için ilaç duyarlılık testleri yapılarak tedavi planının belirlenmesini önermektedir (2).

\section{OLGU SUNUMU}

Mycobacterium abscessus akciğer hastalığı tanısı konulan 55 yaşındaki erkek hasta tedavi başlandıktan sonra klaritromisin ve moksifloksasin alerjisi gelişmesi nedeniyle immünoloji ve alerji hastalıkları kliniğine konsülte edildi. Hastanın öz geçmiş sorgulamasında önceye ait bilinen herhangi alerji öyküsü (ilaç, gıda, lateks vb.) olmadığı görüldü. Yine ocak 2018 tarihinde Mycobacterium abscessus akciğer hastalığı tanısıyla moksifloksasin, klaritromisin, amikasin ve linezolid tedavisi verildiği ve hastanın bu ilaçları sorunsuz olarak kullanıp tedavinin yaklaşık 50 . gününde bu ilaçları kullanmayı bıraktığı öğrenildi. Kasım 2018 tarihinde başvurduğu merkezde moksifloksasin ve klaritromisin yeniden başlandığında, bu iki ilacın eş zamanlı ilk dozlarının alımını takiben beş dakika içinde yüzde kızarıklık, bulantı-kusma, gözlerde kararma, fenalık hissi, nefes darlığı ve soğuk terleme geliştiği öğrenildi. Bu reaksiyondan bir gün sonra hasta tedavi planı açısından kliniğimize konsülte edildi. Açıklanan klinik tablonun anafilaksi ile uyumlu olması nedeniyle bu iki grup ilacın kısıtlan- ması ve farklı tedavi protokolü oluşturulması önerildi. Ancak ilaç duyarlılık testine göre klaritromisin ve moksifloksasinin tedavi rejiminde gerekli olduğu tarafımıza bildirildi. Bu sebeple hastanın ve takipli olduğu tüberküloz kliniğinin onamı alınarak ilgili ilaçlarla cilt testleri yapıldı. Klaritromisin ile $5 \mathrm{mg} / \mathrm{ml}$ (A solüsyonu), 0,5 mg/ml (B solüsyonu), 0,05 mg/ml (C solüsyonu) ve $0,005 \mathrm{mg} / \mathrm{ml}^{\prime}$ lik (D solüsyonu) dört farklı solüsyon oluşturuldu. C solüsyonu ile prik cilt testi, D ve $\mathrm{C}$ solüsyonları ile 20 dakika arayla intradermal cilt testleri yapıldı. Klaritromisin ile yapılan cilt testlerinde duyarlılık izlenmedi. Moksifloksasin ile A $(0,16$ $\mathrm{mg} / \mathrm{ml})$, B $(0,016 \mathrm{mg} / \mathrm{ml})$ ve $C(0,0016 \mathrm{mg} / \mathrm{ml})$ solüsyonları oluşturuldu. Moksifloksasin $(1,6 \mathrm{mg} / \mathrm{ml})$ ile direkt prik cilt testi ve arkasından tarafımızca oluşturulan $C$ ve $B$ solüsyonları ile 20 dakika ara ile intradermal cilt testi yapıldı. Moksifloksasin ile yapılan cilt testlerinde de herhangibir duyarlılık izlenmedi. Hastanın öyküsünün ciddi anafilaktik reaksiyonla uyumlu olması ve cilt testlerinin öngörüsünün zayıf olduğunun bilinmesi nedeniyle desensitizasyon planı oluşturuldu. ilk gün klaritromisin ile desensitizasyon protokolü başarılı şekilde uygulandı (Tablo 1). İşlem öncesi herhangi bir premedikasyon uygulanmadı ve desensitizasyon sırasında hiçbir advers reaksiyon kaydedilmedi. Bu uygulamada Holmes ve arkadaşlarının 2008 yılında yayınladıkları makale örnek olarak kullanıldı. Makrolitlere duyarsızlaştırma için yayınlanan ilk protokoldür (3). Ertesi gün moksifloksasin ile desensitizasyon protokolü başarılı şekilde uygulandı (Tablo 2). İşlem öncesi herhangi bir premedikasyon uygulanmadı ve desensitizasyon sırasında hiçbir advers reaksiyon kaydedilmedi. Bu uygulamada ise Benken ve arkadaşlarının 2017 yılında yayınladıkları literatür örnek olarak alınmıştır. Tüberküloz tedavisinde moksifloksasin ile gerçekleştirilen ilk desensitizasyon olgusudur (4). Hastanın tedavisine moksifloksa- 
Aksu K, Çuhadar Erçelebi D, Özkara Ş, Türkyılmaz S, Koca Kalkan i, Özdedeoğlu Ö ve ark.

Tablo 1. Klaritromisin desensitizasyon protokolü

\begin{tabular}{|c|c|c|c|}
\hline Saat & Doz (mg) & Saat & Doz (mg) \\
\hline 09:30 & 0,005 & $11: 45$ & 3,2 \\
\hline 09:45 & 0,01 & $12: 00$ & 6 \\
\hline 10:00 & 0,02 & $12: 15$ & 12 \\
\hline 10:15 & 0,05 & $12: 30$ & 24 \\
\hline 10:30 & 0,1 & $12: 45$ & 50 \\
\hline $10: 45$ & 0,2 & $13: 00$ & 100 \\
\hline 11:00 & 0,4 & $13: 15$ & 200 \\
\hline 11:15 & 0,8 & $13: 30$ & 400 \\
\hline 11:30 & 1,6 & $13: 45$ & 500 \\
\hline \multicolumn{4}{|c|}{$\begin{array}{l}\text { A solüsyonu: } 50 \mathrm{mg} / \mathrm{ml} \text { klaritromisin. } \\
\text { B solüsyonu: } 5 \mathrm{mg} / \mathrm{ml} \text { klaritromisin. } \\
\text { C solüsyonu: } 0,5 \mathrm{mg} / \mathrm{ml} \text { klaritromisin. } \\
\text { D solüsyonu: } 0,05 \mathrm{mg} / \mathrm{ml} \text { klaritromisin. }\end{array}$} \\
\hline
\end{tabular}

Tablo 2. Moksifloksasin desensitizasyon protokolü

\begin{tabular}{|lc|}
\hline Saat & Doz $(\mathbf{m g})$ \\
\hline $10: 00$ & 0,0004 \\
$10: 30$ & 0,004 \\
$11: 00$ & 0,04 \\
$11: 30$ & 0,4 \\
$12: 00$ & 4 \\
$12: 30$ & 40 \\
$13: 00$ & 100 \\
$13: 30$ & 250 \\
\hline A solüsyonu: $40 \mathrm{mg} / \mathrm{ml}$ moksifloksasin. & \\
B solüsyonu: $4 \mathrm{mg} / \mathrm{ml}$ moksifloksasin. & \\
C solüsyonu: $0,4 \mathrm{mg} / \mathrm{ml}$ moksifloksasin. & \\
D solüsyonu: $0,04 \mathrm{mg} / \mathrm{ml}$ moksifloksasin. \\
E solüsyonu: $0,004 \mathrm{mg} / \mathrm{ml}$ moksifloksasin. \\
F solüsyonu: $0,0004 \mathrm{mg} / \mathrm{ml}$ moksifloksasin. \\
\hline
\end{tabular}

sin, klaritromisin, amikasin ve linezolid kombinasyonu şeklinde sorunsuz olarak devam edildi.

\section{TARTIŞMA}

Antibiyotik aşırı duyarlılığı; önemli morbidite, mortalite ve yetersiz tedavi seçeneklerine yol açabilir. İlaç desensitizasyonu, alternatif ilaç rejimlerinin mevcut olmaması veya mevcut olan rejimlerin uygun olmaması durumunda hastalık süreçlerinin tedavisinde bizlere imkan sunan bir yöntemdir. Hızlı desensitizasyon, tip 1 aşırı duyarlılık reaksiyonu olan bir kişide geçici immünolojik toleransı sağlayabilmektedir. Hızlı desensitizasyon, tedavi edici doza ulaşılıncaya kadar ilacın artan konsantrasyonlarda verilmesidir.
Antijene özgü mast hücre duyarsızlaştırmasının, ilaç desensitizasyonunun altında yatan mekanizma olduğu düşünülmektedir $(5,6)$. Çeşitli antitüberküloz ajanlarla aşırı duyarlılık reaksiyonları meydana gelebilir ve tedavinin kesilmesine neden olabilir $(3,4)$. Mycobacterium abscessus akciğer hastalığında tedavi seçenekleri oldukça kısıtlıdır $(1,2)$.

Mycobacterium abscessus tedavisinde temel ajan olan makrolidler alerjik reaksiyonlar açısından en güvenilir antibiyotik gruplarından biri olmasına rağmen nadiren makrolid aşırı duyarlılığı tedaviyi güçleştirebilir $(7,8)$. Makrolid alerjisinin mekanizması tam olarak bilinmemektedir ve cilt testleri de çoğunlukla negatiftir (8). Literatürde bildirilen ilk klaritromisin desensitizasyon olgusu da bu nedenle cilt testi yapılmaksızın ve hastanın klinik öyküsünün makrolid alerjisi ile uyumlu olması gerekçesiyle klaritromisin desensitizasyonunun gerekli olduğu düşünülerek oral hızlı klaritromisin desensitizasyon işlemi gerçekleştirilmiştir. Desensitizasyon işlemi sırasında herhangi bir olumsuz durumla karşılaşılmamıştır (3). Biz olgumuzda öncelikle cilt testlerini uyguladık. Cilt testlerinde duyarlılık izlenmeyen hastamıza klaritromisin ile desensitizasyon işlemi uygulandı. İşlem basamakları sırasında herhangi bir olumsuzluk izlenmedi.

Kinolon kullanımının son yıllarda hızla artmasına bağlı olarak bu ajanlar ile alerjik reaksiyon gelişme sıklığı da artmaktadır. Kinolon alerjisinin doğru tanınması olgularda sıklıkla öykünün güvenilir olmaması ve cilt testlerinin yanıltıcı olabilmesi nedenleriyle güçtür (9). Moksifloksasinin aşırı duyarlılık reaksiyonlarına neden olduğu bilinmektedir. Hatta florokino- 
Ion ile ilişkili anafilaksi, ajanın ilk alımından sonra ortaya çıkabilir (10). Moksifloksasin, tüberküloz tedavisi için önerilen bir birinci basamak tedavisi olmasa da, başlangıç aşaması tedavisi ile advers ilaç reaksiyonları ortaya çıkarsa, uygulanabilir bir seçenek olduğu gösterilmiştir (11). Tüberküloz hastasında moksifloksasin ile literatürde bildirilen ilk desensitizasyon olgusu Benken ve arkadaşlarının olgusudur. Hastayı tedavi etme aciliyeti, moksifloksasinle yapılan tanısal testlerin zayıf duyarlılığı ve hastanın öyküsünün ilaç alerjisi ile uyumlu olması nedeniyle olguda cilt testleri yapılmadan direkt oral desensitizasyon işlemi uygulanmıştır. Basamak artışları sırasında kaşıntı, göz kapağında şişlik, makülopapüler tarzda kızarıklık, dışkılama aciliyeti ve karın ağrısı şikayetleri izlenmiş ancak hastanın desensitizasyon işlemi başarılı bir şekilde tamamlanmıştır (4). Biz olgumuzda öncelikle moksifloksasin cilt testlerini gerçekleştirdik. Cilt testlerinde duyarlılık izlenmeyen hastamıza moksifloksasin ile desensitizasyon işlemini uygulandık. Hastamızda işlem basamakları sırasında herhangi bir olumsuzluk izlemedik.

Antibiyotik aşırı duyarlılığı saptanan olgularda sorumlu ajanın kullanılmasından kaçınılması gerekmekle birlikte farklı tedavi seçeneği bulunmayan olgularda desensitizasyon gerekli olabilmektedir. Bu amaçla göğüs hastalıkları gibi ilgili klinikler ve alerji klinikleri arasındaki koordinasyonun oldukça önemli olduğu açıktır.

\section{ÇIKAR ÇATIŞMASI}

Yazarlar bu makale ile ilgili herhangi bir çıkar çatışması bildirmemişlerdir.

\section{YAZAR KATKISI}

Anafikir/Planlama: Tüm yazarlar

Analiz/Yorum: Tüm yazarlar

Veri sağlama: Tüm yazarlar

Yazım: Tüm yazarlar

Gözden Geçirme ve Düzeltme: Tüm yazarlar

Onaylama: Tüm yazarlar

\section{KAYNAKLAR}

1. Lee MR, Sheng WH, Hung CC, Yu Cl, Lee LN, Hsueh PR. Mycobacterium abscessus Complex Infections in Humans. Emerg Infect Dis 2015; 21(9): 1638-46.

2. Woods G, Brown-Elliott B, Conville P, Desmond EP, Hall $G S$, Lin G, et al. Susceptibility testing of mycobacteria, nocardiae, and other aerobic actinomycetes; approved standard. $2^{\text {nd }}$ ed. Wayne, PA: Clinical and Laboratory Standards Institute (CLSI publication no. M24-A2), 2011.

3. Holmes NE, Hodgkinson M, Dendle C, Korman TM. Report of oral clarithromycin desensitization. $\mathrm{Br} / \mathrm{Clin}$ Pharmacol 2008; 66(2): 323-4.

4. Benken ST, Nyenhuis SM, Dunne S. Sequential rapid oral desensitization to rifampin and moxifloxacin for the treatment of active mycobacterium tuberculosis. I Allergy Clin Immunol Pract 2017; 5(1): 195-7.

5. Woo HY, Kim YS, Kang NI, Chung WC, Song CH, Choi IW, et al. Mechanism for acute oral desensitization to antibiotics. Allergy 2006; 61(8): 954-8.

6. Castells M. Desensitization for drug allergy. Curr Opin Allergy Clin Immunol 2006; 6(6): 476-81.

7. Brown-Elliott BA, Wallace RJ Jr. Clinical and taxonomic status of pathogenic nonpigmented or late-pigmenting rapidly growing mycobacteria. Clin Microbiol Rev 2002; 15(4): 716-46.

8. Araújo L, Demoly P. Macrolides allergy. Curr Pharm Des 2008; 14(27): 2840-62.

9. McGee EU, Samuel E, Boronea B, Dillard N, Milby MN, Lewis SJ. Quinolone allergy. Pharmacy (Basel) 2019; 7(3): E97.

10. Sachs B, Riegel S, Seebeck J, Beier R, Schichler D, Barger $A$, et al. Fluoroquinolone-associated anaphylaxis in spontaneous adverse drug reaction reports in Germany: differences in reporting rates between individual fluoroquinolones and occurrence after first-ever use. Drug Saf 2006; 29(11): 1087-100.

11. Gillespie SH. The role of moxifloxacin in tuberculosis therapy. Eur Respir Rev 2016; 25(139): 19-28. 